now the favourite colour for these cattle, the ears of which droop more than in the Mysore type. Although probably less hardy than the Mysore breeds, these cattle are unsurpassed for slow work, a pair, it is stated, being capable of drawing a load of five tons.

The volume closes with a notice of the domesticated buffaloes of southern India, special mention being made of the Toda customs associated with the cult of these animals.

R. L.

Flora of Cornwall. Being an Account of the Flowering Plants and Ferns found in the County of Cornwall, including the Scilly Isles. By F. H. Davey. Pp. 1xxxviii +570 . (Penryn: F. Chegwidden, Igog.) Price 21 s. net.

ON account of its extreme situation, the mildness of the climate, and the interesting rock formations, notably round the Lizard, the county of Cornwall exercises a great fascination for students interested in natural history. It is rather strange, therefore, that a county flora should only now be compiled, especially as many botanists-natives, aliens, and others-have found it a profitable hunting ground. Six years ago Mr. Davey published a preliminary list of plants which was deserving of the title of a flora, but this was only intended to form a basis for a more complete survey and to arouse interest in the undertaking; the intention has been entirely successful, and the author's subsequent labours, assisted by energetic and able co-workers, have culminated in the volume under notice, in which the total number of plants is computed at II80; and of these, 953 are considered to be native.

The greater part of the book is devoted to the enumeration of species, with detailed list of localities for all but very common plants; in this matter the author has been over-bountiful, and space could have been saved by the elimination of the long list of localities for certain species that are in no sense critical, such as Spiranthes autumnalis or Centranthus ruber. The number of species found in Cornwall, but not recorded for any other county in Britain, amounts to twenty, while a comparison with Devonshire shows that fifty-three plants growing in Jornwall have not been collected in Devonshire, as against Io3 confined to the latter county.

A considerable part of the introduction is given up to a history of botanists who have contributed to the county rccords, and a few photographs of notable local botanists are included; there is also a short account of eight botanical districts which are indicated on an accompanying map, and a list of a few plants peculiar to each, but the author has not attempted an ecological sketch of the chief formations. Among the Cornish botanists the best-known name is that of the Rev. C. A. Johns, the author of "Flowers of the Field" and "A Week at the Lizard," while William Curnow, T. R. Archer Briggs, and Richard Tellam were even more zealous field workers. Mr. Davey, too, has added his quota of records, for which he deserves to rank among the honoured list of local botanists, as also for the strenuous work in connection with this publication. The volume is worthy to rank with the standard county floras, more particularly in the verification of records and critical compilation.

The Elements of Animal Physiology. By Prof. W. A. Osborne. Pp. I52. (Melbourne: Thomas C. Lothian, I909.)

THE size of this little book will indicate that it conains a mere sketch of the large subject of which it treats. It is written for the purpose of supplying non-medical readers with an introductory account of mammalian physiology, in the hope that they subse- quently will take up the question more fully. Prof. Osborne has in Melbourne to teach students of agriculture and veterinary science, in addition to those who are taking full medical or science courses, and it is to the former class of students that the work is specially addressed. One can hardly doubt that agriculturists, especially in Australia, where the breeding of domestic animals forms such a large part of their work, will benefit greatly if they have a rational substratum of physiological facts at their disposal.

The book is trustworthy and free from errors; it is specially full on its biochemical side, which is what one would anticipate from Prof. Osborne's research work. Complex questions, such as those dealing with the nervous system, are treated with extreme brevity, and this is to be regarded as judicious, seeing what class of readers are specially catered for. We wish the book the success it deserves.

\section{A Text-book of Experimental Physiology for Students} of Medicine. By Dr. N. H. Alcock and Dr. F. O'B. Ellison. With a preface by Prof. E. H. Starling, F.R.S. Pp. xiitI39. (London: J. and A. Churchill, 1909.) Price 5s. net.

To some extent this little book is the outcome of a conference of the London teachers of physiology. They have for long felt that a revision of their practical courses was necessary, and the present work, which is issued under the agis of Prof. Starling, indicates the kind of reform considered desirable. One understands that in the future the practical examinations in the University of London, at any rate, will be largely modelled on the kind of course here presented. The main underlying new idea is that medical students should be taught physiology so as to fit them for being, not expert pure physiologists, but medical men with a knowledge of those portions of the vast subject which will be immediately useful to them in their study and treatment of diseased conditions. The frog is therefore relegated to a position of subsidiary importance, and as many experiments as possible are given in which the mammal, and especially man himself, is the corpus vile. It would be ungracious at this stage to point out faults of omission and commission of which the authors, Drs. Alcock and Ellison, have been guilty in their praiseworthy attempt to carry out the new idea. It will only be possible to do so when the book has been tried as a practical guide, and future editions will no doubt, show various improvements, after the present one has been subjected to this test. W. D. H.

Elementary Photo-micrography. By Walter Bagshaw. Second edition. Pp. 103. (London: Iliffe and Sons, Ltd., Igog.) Price 2s. 6d. net.

THe object of this little book is to arouse interest in, and give instruction to, those to whom such a study would otherwise possibly appear far too abstruse and full of difficulty. It is most clearly. and lucidly written, and there is an evident desire to avoid unnecessary detail. It would be easy to criticise and to point out the many omissions of essential detail that to an advanced worker are only too obvious; , but it must be admitted that for the beginner and intelligent worker the instructions would prove, in the majority of cases, ample. . Nearly the whole of the course of work suggested may be carried out with simple apparatus : in fact, it is much to the credit of the writer that simplicity, and the absence of any recommendation to use complex apparatus, is the keynote of the entire book. It is perhaps to be regretted that, having gone so far, he has not in some directions slightly extended the work. The instructions in the use of the microscope itself are perhaps unnecesNO. 209I, VOL. 82] 
sarily meagre, whereas such matter as a list of photographic chemicals required, with the prices-information that can be obtained from any trade cataloguemight easily have been omitted. On the whole, however, the object of the book is fulfilled, and it will form, to those who have a microscope of simple construction, or who, having a camera, wish to apply it for microscopic work as well, a most useful guide. The illustrations are in all cases of a high order, and have been selected, not merely as pictorial examples of photo-micrographic work, but, so far as passible, to bring home to the student the difficulties to be encountered and the results to be attained.

\section{J. E. Barnard.}

\section{LETTERS TO THE EDITOR.}

[The Editor does not hold himself responsible for opinions expressed by his correspondents. Neither can he undertake to return, or to correspond with the writers of, rejected manuscripts intended for this or any other part of NATURE. No notice is taken of anonymous communications.]

\section{The Inheritance of Acquired Characters.}

IN reviewing Prof. Eigenmann's book on the cave vertebrates of America (NATURE, November it, p. 4o), the reviewer quotes the author's opinion that "The bleached condition of animals living in the dark, an individual environmental adaptation, is transmissible, and finally becomes hereditarily fixed. . . . Natural selection cannot have affected the coloration of the cave forms, for it can be of no consequence whether a cave species is white or black." Your reviewer further dismisses Romanes's supposition that colour may be correlated with other structures which are subject to selection.

Is it not probable that the mere cessation of natural selection with regard to colour would produce this colourless condition quite apart from light or other environmental factor?

In the silkworm moth, Bombyx mori, we have a similar absence of colour in both moth and larva, solely, I take it, because no attention has been paid to the colour of either during the many centuries that the species has been selected for its silk-producing qualities alone under semidomestication.

While on this subject, I may perhaps refer to $\mathrm{Mr}$. Wm. Wood Smyth's letter in Nature of May 6 last (vol. lxxx., No. 2062, p. 277), with reference to the drone breeding habits of some workers of the hive bee affording a possible channel for use inheritance in regard to neuter characters.

I had hoped that this important point would have been the subject of further correspondence by the acknowledged authorities on apiculture.

I thought that this feature of egg-laying workers was, as a rule, confined to queenless hives that were more or as in extremis. Presumably the habit would be subject to heredity, and if, as I understand, it is not only a detriment but a source of danger to any community of bees to have any number of egg-laying workers, it seems reasonable to suppose that in. wild stocks such a habit would be so stringently restricted by natural selection as to deprive its occasional occurrence in domesticated stocks of any significance in the production of the structural differences or special habits which differentiate workers from queens. It would be of very great interest to know if neuter ants of any species retain the power of laying occasional eggs.

\section{A. ВАСОT.}

MR. BACOT's suggestion with regard to the cessation of natural selection in relation to the bleaching of cave animals has been fully dealt with by Prof. Eigenmann himself in the work under review. It will be only fair to Prof. Eigenmann to quote his own words:- "Panmixia can not account for the discharge of the colour, since it returns in some species when they are exposed to the light and disappears to a certain extent in athers when kept in the dark.
Panmixia, Romanes thinks, may have helped to discharge the colour. In many instances the colour is a protective adaptation, and therefore maintained by selection. Panmixia might in such instances lower the general average to what has been termed the 'birth-mean.' Proteus is perhaps such an instance. But in this species the bleached condition has not yet been hereditarily established, and since each individual is independently affected, "the main cause of change must have been of that direct order which we understand by the term climatic.' Since, however, the bleached condition, which in the first instance is an individual reaction to the absence of light, has become hereditarily established in Amblyopsis so that the bleaching goes on even, when the young are reared in the light, it is evident that in Amblyopsis we have the direct effect of the environment on the individual hereditarily established."

If Mr. Bacot will read the notice again he will see that the reference to "Romanes's supposition that colour may be correlated with other structures which are subject to selection " is a quotation. The reviewer still considers, however, that Prof. Eigenmann has made out a strong case.

Arthur Dendy.

\section{Radio-activity and the Rocks.}

Mr. F. P. Mennell, in Nature of November 18 raises the question whether the more strongly active of the rock-forming minerals owe their activity to thorium. I have a considerable number of data on this subject obtained by direct experiment, estimating radium and thorium by their emanations. I find, by this method; that zircon, sphene, and apatite usually contain some thorium, but that it generally contributes less to the activity than the substances of the uranium-radium series. Imperial College of Science, South Kensington,
November 20.

\section{The Auroral Display of October 18.}

The aurora of October 18 was observed at Allegheny Observatory under conditions somewhat similar to those mentioned by Mr. Ernest Baty in NATURE of October 28 (vol. Ixxxi., p. 518). Here, however, the whole sky was dull, hazy, and cloudy at the beginning of the display. gradually clearing toward midnight. No stars whatever could be seen in the region covered by the aurora, which was very bright. This fact might lead us to think that it had its origin in the lower layers of the atmosphere.

The aurora consisted of the usual arch, from which arose streamers at various points, some of them extending to an altitude of about $45^{\circ}$. These drifted westward and gradually diminished in brightness, while they were followed by others in rapid succession. The streamers had at times a reddish tint

The aurora was still faintly visible at I a.m., by which time the sky had become perfectly clear.

Allegheny Observatory, Allegheny, $\mathrm{Pa}$.

F. C. Jordan. November 9

\section{Large Flying-fish.}

A FLYING-FISH flew on to the lower deck last night about $8.30 \mathrm{p} . \mathrm{m}$. The deck is 20 feet above the waterline, and the railing is 4 feet 6 inches above the deck, but it is possible for it to have flown through the railing; the fish measured $17^{\frac{1}{4}}$ inches from tip of nose to tip of tail. I forgot to weigh it before it was cooked. It was the largest flying-fish $I$ have ever handled. Could any reader of NATURE kindly inform me what is the largest size known? We were about fifty miles north of Teneriffe when it came on board. The species up here appear to be larger than those in the tropics and near South America. I have seen large ones in the Gulf of Aden, but never caught one, though I am inclined to think this was a larger species. The longest flyers always appear to be the largest fish; the longest flight I have seen has been about 400 yards.

S.S. Kaipara, October 15 .

NO. 209I, VOL. 82] 